\title{
Obstructive jaundice as a complication of a peptic duodenal ulcer mimicking pancreatic cancer
}

A 56-year-old man was admitted to our gastroenterology department for upper gastrointestinal bleeding. The patient was a heavy smoker and drank an average of $50 \mathrm{~g}$ of ethanol per day. On urgent upper endoscopy, an active bleeding ulcer was observed in the upper wall of the first duodenal flexure. In spite of therapeutic sclerosis with epinephrine $1: 10000$ (4 mL) and etoxiesclerol 2\% (4 mL) the ulcer bled again. After a second unsuccessful attempt at therapeutic endoscopy with injection of epinephrine $1: 10000(6 \mathrm{~mL})$ and etoxiesclerol $2 \%$ ( $4 \mathrm{~mL}$ ) the patient was operated and the bleeding point sutured. After 2 months, the patient was readmitted for painless obstructive jaundice. An abdominal computed tomography (CT) scan showed dilated intra- and extrahepatic bile ducts (up to the intrapancreatic portion) and an increase in the size of the pancreatic head with an ill-defined hypodense area measuring $21 \times 13 \mathrm{~mm}$ ( $\bullet$ Fig. 1).

During endoscopic ultrasonography (EUS), a duodenal bulb ulcer with inflammation and mild stenosis of the duodenal flexure was observed. The EUS also revealed a lesion, $20 \times 15 \mathrm{~mm}$, with spiculated margins in the head of the pancreas and contiguous with the thickened duodenal wall ( $\bullet$ Fig. 2).

Endoscopic biopsies and the cytologic examination of the material obtained by EUS-guided fine-needle aspiration were negative for malignant cells. Percutaneous cholangiography performed shortly afterward showed abrupt obstruction of the distal bile duct. Surgery was finally required to treat the biliary obstruction and a cephalic duodenopancreatectomy was performed. Histological study of the surgical specimen showed a duodenal ulcer with scarring retraction involving the pancreatic head and distal bile duct, but with no malignant infiltration ( $\bullet$ Fig. 3 ). The postoperative course was favorable, and 3 months after the operation the patient was asymptomatic and generally well.

Obstructive jaundice secondary to a local pancreatic lesion has been related to malignant pancreatic tumors or to pseudotumors of inflammatory etiology, such as chronic pancreatitis [1]. Bile obstruction

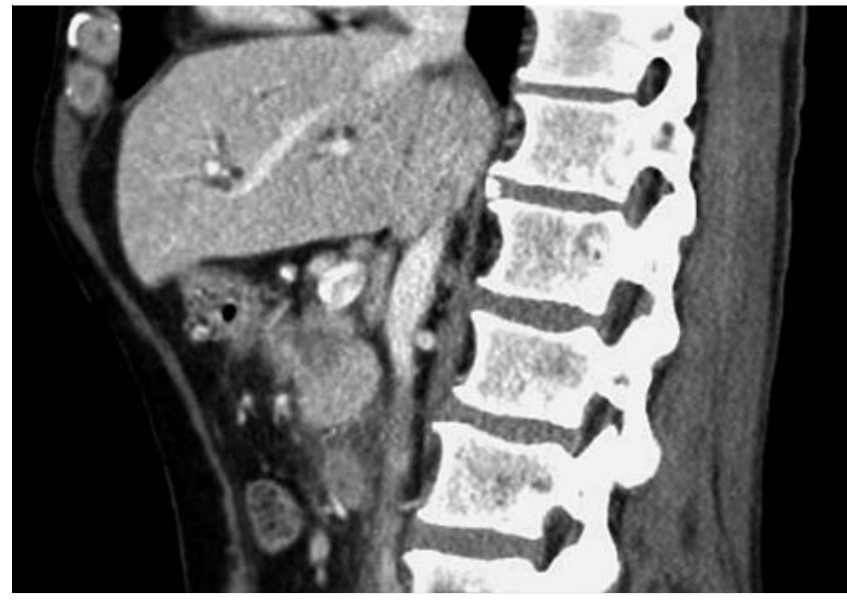

Fig. 1 A hypointense lesion visible in the pancreatic head on an abdominal computed tomography (CT) scan.

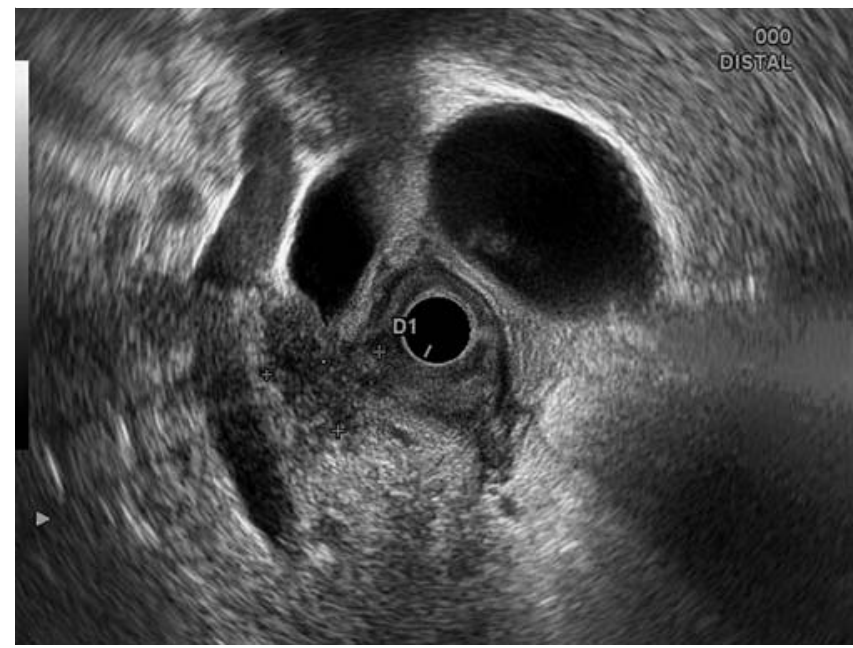

Fig. 2 A localized lesion visible in the pancreatic head on radial endoscopic ultrasonography. The lesion is contiguous with the thickened duodenal wall and is causing bile duct obstruction.

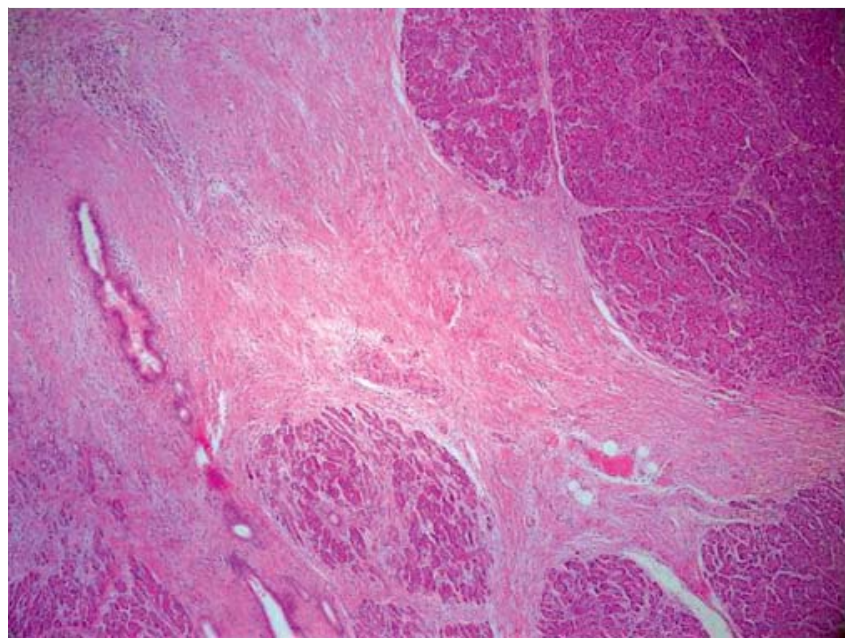

Fig. 3 Histological section showing pancreatic tissue replaced by fibrous scar retraction with starlike morphology mimicking an infiltrating tumor (hematoxylin and eosin, original magnification $\times 200$ ).

as a complication of the treatment of a peptic ulcer is rare. Recently, this complication has been shown to be the result of a peri-ulcerous inflammatory component [2] or the result of hemostatic treatment using sclerotic substances [3]. 
Competing interests: None

Endoscopy_UCTN_Code_CCL_1AF_2AZ_3AB Endoscopy_UCTN_Code_CCL_1AZ_2AZ

L. Hidalgo ${ }^{1}$, A. Repiso', M. Romero ${ }^{1}$, J. Navajas ${ }^{1}$, R. Sánchez-Simón'², R. Gómez-Rodríguez ${ }^{1}$, J. M. Carrobles ${ }^{1}$

1 Gastroenterology Department, Virgen de la Salud Hospital, Toledo, Spain

2 Anatomical Pathology Department, 'Virgen de la Salud' Hospital, Toledo, Spain

\section{References}

1 Tony E, Yusuf MD, Manoop S, Bhután MD. Differentiating pancreatic cancer from pseudotumorous chronic pancreatitis. Curr Gastroenterol Reports 2002; 4: 135-139

2 Chiu-Yung H, Tseng-Shing C, Full-Young C, Shou-Dong $L$. Bening nontraumatic inflammatory stricture of mid portion of common bile duct mimicking malignant tumor: Report of two cases. World J Gastroenterol 2004; 10: $2153-2155$

3 Luman W, Hudson N, Choudari CP et al. Distal biliary stricture as a complication of sclerosant injection for bleeding duodenal ulcer. Gut 1994; 35: 1665 - 1667

\section{Bibliography}

DOI $10.1055 / \mathrm{s}-0030-1255785$

Endoscopy 2010; 42: E294-E295

(c) Georg Thieme Verlag KG Stuttgart · New York . ISSN 0013-726X

\section{Corresponding author} L. Hidalgo

Digestive System Services Virgen de la Salud Hospital Avda Barber 30 45004 Toledo Spain

loha1983@hotmail.com 